RELACult - Revista Latino-Americana de Estudos em Cultura e Sociedade

\title{
História Das Políticas Culturais Para Mulheres No Brasil
}

\section{Historia de las politicas culturales para las mujeres en el Brasil}

\author{
History of cultural politics for women's in Brazil
}

\author{
Milena Cristina Almeida ${ }^{1}$ \\ Allan Mateus Cereda ${ }^{2}$
}

\begin{abstract}
Resumo
O presente artigo visa trazer um breve panorama da história das políticas culturais no Brasil e as políticas culturais voltadas especificamente para as mulheres. A pesquisa traz uma cronologia dos avanços e retrocessos das políticas culturais brasileiras implementadas por diversos governos. $\mathrm{O}$ artigo está divido em dois capítulos, o primeiro aborda amplamente as políticas culturais e o segundo mais especificamente voltada para as mulheres.
\end{abstract}

Palavras-Chave: História das Políticas Culturais; Política Cultural para Mulheres; Política Cultural; Políticas Culturais no Brasil; Tristes Tradições.

\section{Resumen}

En este artículo se pretende llevar un breve resumen de la historia de las políticas culturales en el Brasil y también a las políticas culturales para las mujeres. La investigación proporciona una cronología de los avances y contratiempos de las políticas culturales brasileñas por varios gobiernos. El artículo se divide en dos capítulos, el primero es sobre las políticas culturales y el segundo es sobre las las políticas para las mujeres.

Palabras clave: Historia de la Política Cultural; Política Cultural para la Mujer; Política cultural; Políticas culturales en el Brasil; Tradiciones triste.

\begin{abstract}
The present article intends to bring a brief historic overview about the Brazilian cultural politics, especially those for women. This research brings a chronology of the advances and setbacks on cultural politics implemented by several governments in Brazil. The article is split into two chapters, the first one explores the cultural politics broadly, and the second one is turned specifically to women's cultural politics.
\end{abstract}

Keywords: history of cultural politics; women's cultural politics; cultural politics; cultural politics in Brazil; sad traditions.

\section{Introdução}

A elaboração dessa pesquisa parte da tentativa de atualizar o campo de estudos da história das políticas culturais no Brasil, área essa que apresenta poucos/as pesquisadores/as

\footnotetext{
${ }^{1}$ Universidade Federal do Pampa; Rio Grande do Sul, Brasil; micrismeida@gmail.com

${ }^{2}$ Universidade Federal do Pampa; Rio Grande do Sul, Brasil; allan.cereda@gmail.com
} 
desenvolvendo estudos específicos. Partindo de um breve panorama do inicio das políticas culturais no Brasil em 1930, passando por diversos governos que apresentam ações que avançam na consolidação da cultura e outras que retrocedem na estabilização do campo cultural.

Ao longo da história das políticas culturais no Brasil, diversos órgãos e instituições foram criados, em outros momentos dizimados, às vezes restabelecidos, alguns transformados e por vezes fundidos. Leis foram promulgadas, algumas reformuladas e outras extintas. Diferentes nomes passaram pela gestão da política cultural brasileira na tentativa de solidificar e valorizar o campo cultural.

Existe também a necessidade de registrar a fragilidade do atual momento que a cultura do país está passando. Com o governo interino de Michel Temer, houve um abalo nas estruturas da Cultura, ao assumir o lugar da Presidenta Dilma, através do impeachment, Temer desfaz o Ministério da Cultura. Movimentos de artistas, e pessoas envolvidas com a cultura de diversos lugares do país não aceitaram essa medida arbitrária e pressionaram o governo contra essa atitude, que fez Michel Temer voltar atrás sobre a decisão de englobar o $\underline{\text { MinC }}$ com o MEC. O ministro nomeado foi Marcelo Calero.

No que diz respeito às políticas culturais específicas para as mulheres, algumas poucas ações são proporcionadas, que acabam por serem insuficientes diante da demanda que existe. Nós mulheres, somos cerca de $50 \%$ da população brasileira e proporcionalmente existem poucos trabalhos culturais e artísticos protagonizados por mulheres. Na tentativa de valorização das mulheres e da desconstrução de estereótipos, dando maior visibilidade à produção cultural feminina, existem alguns editais voltados para o fomento da cultura desenvolvidos por mulheres no Brasil. Essas ações são pensadas junto com a SPM (Secretaria de Política para as Mulheres), que o Presidente interino Michel Temer ameaçou extinguir.

\section{Breve histórico das políticas culturais no Brasil}

No Brasil, para Albino Rubim (2007, p.11), a história das políticas culturais é caracterizada por tristes tradições - ausências, autoritarismos e instabilidades - que tem como consequências: descontinuidades, impasses e muitos desafios. As políticas culturais no Brasil têm início tardiamente. A inauguração das políticas culturais ocorre a partir de duas situações, "a passagem de Mário de Andrade pelo Departamento de Cultura da Prefeitura da cidade de São Paulo (1935-1938) e a implantação do Ministério da Educação e Saúde, em 1930" (RUBIM, 2007, p.15). 
Mario de Andrade apresenta inúmeras novidades para tentar afirmar o cenário cultural do Brasil, abrangendo seu planejamento para diversas áreas culturais, entendendo a cultura enquanto direito de todas e todos, inovando também na maneira de compreensão de patrimônio - não só como material, mas também o intangível. Novidades essas que apresentam problemas e dificuldades, "mas tais limitações não podem obscurecer a exuberância e criatividade deste marco inicial das políticas culturais no Brasil" (RUBIM, 2007, p.16).

O então ministro Gustavo Capanema, responsável pelo setor cultural no governo Vargas (1934-1945), quase que simultaneamente, articulava intervenções na área da cultura e a criação de instituições, como por exemplo: Serviço do Patrimônio Histórico e Artístico Nacional (SPHAN) em 1937, Instituto Nacional do Livro (INL) em 1937, Instituto Nacional de Cinema Educativo (INCE) em 1936 - dando condições para "a regulação do emprego de parte da produção cinematográfica" (CALABRE, 2005, p.3). Outra área que avançou foi a da radiodifusão, com a promulgação da legislação específica em 1932 - quase 10 anos depois que a primeira emissora de rádio brasileira foi ao ar. Conforme Albino Rubim (2007, p.18), mesmo com esses movimentos, a gestão inauguradora de Vargas e Capanema ainda demonstra ausências e carências de diversas ordens e cria uma forte relação entre governos autoritários e politicas culturais.

Entre 1945 e 1964, Calabre (2005, p.3) afirma que na área da cultura o grande desenvolvimento se deu pela iniciativa privada. Em 1953, ocorre o desmembramento do Ministério da Educação e Saúde em Ministério da Saúde (MS) e Ministério da Educação e Cultura (MEC). Albino Rubim (2007, p.19) apresenta as intervenções do período, como o Movimento de Cultura Popular, em Recife no ano de 1960 e no estado de Pernambuco em 1963 e bloqueado pelo Golpe Militar em 1964; e os Centros Populares de Cultura (CPC) da União Nacional dos Estudantes (UNE), no Rio de Janeiro em 1961 que movimentou os desejos culturais e políticos dos estudantes brasileiros, também eram bastante polêmicos e acabaram fechados em 1964. Esse período apresenta uma falsa sensação de que estamos numa abertura cultural, porém com o Golpe Militar de 1964 a repressão e a censura toma conta da área cultural e ocasionou o "desmantelamento da grande maioria dos projetos culturais em curso" (CALABRE, 2005, p.4).

Durante o governo de Castelo Branco (1964-1967), segundo Calabre (2005, p.4) não foram registrados avanços na discussão da elaboração de uma politica nacional de cultura. Mas houve, em 1966, a criação do Conselho Federal de Cultura e a criação do Instituto Nacional de Cinema (INC) - tinha como objetivo fomentar políticas relativas à produção, 
importação, distribuição e exibição de filmes - que englobou o Instituto Nacional de Cinema Educativo (INCE) de 1936. Para Albino Rubim (2007, p.20) esse período da ditadura é o momento da cultura dominada por uma dinâmica de cultura midiatizada, implementando a lógica da indústria cultural a partir da criação de empresas como a Telebrás e a Embratel, controlando os meios audiovisuais e manipulando, mesmo que de maneira simbólica, as massas.

No governo Médici (1969-1974), em 1970 ocorre à transformação do SPHAN em Instituto do Patrimônio Histórico e Artístico Nacional (IPHAN). Lia Calabre (2005, p.4) apresenta que durante a gestão do Ministro Jarbas Passarinho (1969-1973), foi formulado o Plano de Ação Cultural (PAC), lançado em 1973, projeto que financiaria, na época, eventos culturais, além de contemplar o setor de patrimônio e capacitação de pessoas. O plano teve um importante papel na descentralização cultural, através da diversidade de artistas que se deslocavam para outros locais do país, circulando por todas as regiões brasileiras a partir da meta de "implementação de um ativo calendário de eventos culturais, com espetáculos nas áreas de música, teatro, circo, folclore e cinema" (CALABRE, 2005, p.4). Albino Rubim (2007, p.21) aposta que esse é o segundo momento da ditadura, o mais brutal, a censura barra todo o desenvolvimento cultural anterior.

O próximo período (1974-1978) no governo Geisel com a gestão do Ministro Ney Braga, novos investimentos foram feitos. Foi criado o Plano Nacional de Cultura (PNC) em 1975. "A ideia central do PNC era a da organização de um sistema que pudesse coordenar a ação dos vários organismos no campo da cultura, valorizando a produção cultural nacional." (CALABRE, 2005, p.5). Órgãos também foram criados, como o Conselho Nacional de Direto Autoral (CNDA), Centro Nacional de Referência Cultural (CNRC) também em 1975, idealizado e dirigido por Aloísio Magalhães. Em 1976 foi criado o Conselho Nacional de Cinema e a Radiobrás e a reformulação da Embrafilme. Houve a criação da Fundação Nacional das Artes (FUNARTE) em 1975 - “criada para ser um dos órgãos executores dessas novas diretrizes políticas do governo" (CALABRE, 2005, p.5) “e paulatinamente consolida-se como um organismo com intervenções bastante inovadoras no campo cultural." (RUBIM, 2007, p.22).

Na gestão do Ministro Eduardo Portella (1979-1980), com a transformação do IPHAN para Secretaria do Patrimônio Histórico Nacional, Aloísio Magalhães assume o cargo de direção. Em 1979 a criação da Fundação Nacional Pró-Memória incorporou o CNRC. Para Albino Rubim (2007, p.23), mesmo com planos inovadores para as políticas culturais 
brasileiras, com as tensões e problemas, ainda sim é reafirmada a triste tradição do autoritarismo com as políticas culturais.

\begin{abstract}
"Outra vez mais, reafirma-se a problemática tradição, com a conexão entre autoritarismo e políticas culturais. Ainda que a maior parte da atuação do Estado tenha acontecido na fase de transição da ditadura, sua configuração continua sendo moldada por parâmetros do regime autoritário, em declínio. A ditadura também realiza a transição para a cultura midiática, assentada em padrões de mercado, sem qualquer interação com as políticas de cultura do Estado. Em suma: institui-se um fosso entre políticas culturais nacionais e o circuito cultural agora dominante no país" (RUBIM, 2007, p.23).
\end{abstract}

Lia Calabre (2005, p.7) expõe que o fortalecimento e a consolidação de partes do campo da cultura ocorreram entre 1979 e 1985. A Secretaria de Cultura foi criada na gestão do Ministro Rubem Ludwig em 1981 e incorporou a Secretaria de Assuntos Culturais (SEAC) e a área de patrimônio. Ainda neste período foi planejado o plano de diretrizes para operacionalização da política cultural no MEC. Albino Rubim (2007, p.23) discorre sobre a trajetória de Aloísio Magalhães que vinha planejando e organizando o cenário cultural para, no futuro, construir o Ministério, porém essa elaboração foi interrompida com seu falecimento em 1982. Mas em 1985, o Ministério da Cultura (MinC) é então criado e "como alguns previam, as verbas ficaram majoritariamente com a educação, compondo um quadro de um futuro pouco promissor para a cultura" (CALABRE, 2005, p.7).

No ano de 1986, o Presidente Sarney promulgou a Lei $n^{\circ} 7.505$, durante a gestão do Ministro Celso Furtado. Conhecida como Lei Sarney, foi a primeira lei brasileira de incentivos fiscais para cultura e permitia abater do Imposto de Renda doações, patrocínios e investimentos em cultura. No período de 1986 e 1988 foram criados diversos órgãos culturais, como: Secretarias de Apoio à Produção Cultural (1986); Fundação Nacional de Artes Cênicas (1987); Fundação do Cinema Brasileiro (1987); Fundação Nacional Pró-Leitura, reunindo a Biblioteca Nacional e o Instituto Nacional do Livro (1987) e Fundação Palmares (1988).

A desestruturação do campo cultural acontece principalmente no governo Fernando Collor. Logo no início de seu mandato em 1990, Collor extingue a FUNARTE, Pró-Memória, FUNDACEN, FCB, Pró-Leitura e a EMBRAFILMES - criada em 1969. "Todo o processo foi feito de maneira abrupta, interrompendo vários projetos, desmontando trabalhos que vinham sendo realizados por mais de uma década." (CALABRE, 2005, p.7). Collor não parou de afundar a cultura brasileira, revogou a Lei Sarney e logo em seguida transformou o MinC em Secretaria, que teve como primeiro Secretário Ipojuca Pontes e em 1991 Sérgio Paulo Rouanet assume. "A completa desestruturação da intervenção do Estado no campo cultural e, em especial, cinematográfico, teve um impacto brutal sobre a produção cultural e cinematográfica.” (RUBIM, Linda. 2007. p.3). Em 1991, o governo Collor da origem à outra 
lei de incentivo à cultura, a Lei ${ }^{\circ}$ 8.313, conhecida como Lei Rouanet. Para Albino Rubim (2007, p.25) esta nova lógica de financiamento é um recurso quase de todo público, mas que o poder de decisão é da iniciativa privada, potencializando a intervenção do mercado e eximindo o Estado da responsabilidade com as políticas culturais.

\footnotetext{
"Em vez, de financiamento direto, agora o próprio Estado propunha que os recursos fossem buscados pretensamente no mercado, só que o dinheiro em boa medida era público, decorrente do mecanismo de renúncia fiscal. (...) Outra vez mais a articulação entre democracia e políticas culturais se mostrava problemática. $\mathrm{O}$ Estado parecia persistir em sua ausência no campo cultural em tempos de democracia." (RUBIM, Albino. 2007. p. 24 e 25).
}

Final de setembro de 1992 acontece a queda do Collor através do processo de impeachment, Itamar Franco - vice do Collor na época - assume a presidência, recria o Ministério da Cultura nomeia como Ministro Antônio Houaiss e o quadro cultural aos poucos começou a modificar. A nova estrutura do Ministério mantinha como entidades vinculadas a Fundação Casa de Rui Barbosa, a Fundação Nacional de Arte, a Fundação Biblioteca Nacional, a Fundação Cultural Palmares e o Instituto do Patrimônio Histórico e Artístico Nacional.

Em 1994, após eleito, Fernando Henrique Cardoso revisa a Lei Rouanet que começa a ser efetivamente aplicada. Na gestão do Ministro Francisco Weffort (1995-2002) “o governo federal diminuiu o nível dos investimentos públicos na área da cultura, repassando para a iniciativa privada a responsabilidade de decisão sobre os rumos da produção cultural.” (CALABRE, 2005, p.8). Em relação ao financiamento da cultura, segundo Albino Rubim (2007) o financiamento via leis de incentivo é predominante, na gestão de Weffort. Em 1995 235 empresas usavam as leis, em 1996 eram 614 empresas, 1133 empresas usufruíam das leis de incentivo em 1997, 1061 empresas em 1998 e 1040 no ano de 1999. “As leis de incentivo tornaram-se a política cultural do Ministério da Cultura na gestão do Presidente Fernando Henrique Cardoso e do Ministro Francisco Weffort." (CALABRE, 2005, p.8).

Em 2002, o Governo Lula juntamente com o Ministro Gilberto Gil, enfrentam muitos desafios e segundo Albino Rubim (2007, p.29) complicadas tradições relacionadas ao autoritarismo e intervenções do estado na cultural, além de uma fragilidade e políticas de financiamento da cultura completamente reféns das leis de incentivo. O então Ministro Gil, discursa sobre reivindicar um conceito de cultura mais alargado, onde o público privilegiado seria a sociedade brasileira, retomando o papel ativo do Estado nas políticas culturais, buscando trabalhar em novas áreas. O Ministério também ampliou suas atividades 
relacionadas à economia da cultura e os indicadores culturais, promovendo debates e seminários. Ocorreu a instalação de um Centro Internacional de Economia Criativa no Brasil, e o Fundo Nacional de Cultura passou a ter base na concorrência de projetos e o uso de editais para apoio à cultura, e as leis de incentivo foram reformuladas.

Albino Rubim (2007, p.31), destaca alguns projetos importantes nesse período, como a constituição de um Sistema Nacional de Cultura, o Plano Nacional de Cultura como política de Estado, a criação de Câmaras Setoriais e o programa de Pontos de Cultura. Mas ao mesmo tempo aponta um dos principais obstáculos do Ministério, a formação de pessoal qualificado para atuar na organização da cultura.

No ano de 2014, Dilma Rousseff é reeleita - primeira eleição foi em 2010 - tendo como vice-presidente Michel Temer. Final de 2015, mais precisamente em dezembro, inicia um processo de impeachment da então Presidenta do Brasil Dilma Rousseff. Em 17 de abril de 2016 o plenário da Câmara dos Deputados aprovou o relatório de impedimento da Presidenta com 367 votos favoráveis e 137 contrários, levando assim o processo para o senado. No dia 12 de maio de 2016 o Senado também aprovou o processo por 55 votos a favor e 22 contra, afastando Dilma Rousseff da presidência do país até a conclusão do procedimento. Com o afastamento da Presidenta, o vice, Michel Temer assume a presidência.

Michel Temer começa o desmonte da cultura logo que assume o cargo de Presidente interino do Brasil. Anuncia a extinção do MinC e abrindo uma pasta de cultura no MEC. Diversos artistas, agentes culturais, intelectuais e movimentos sociais não aceitaram esse retrocesso autoritário de Temer e se manifestaram pressionando que o governo voltasse atrás dessa decisão. Michel Temer então recria o Ministério da Cultura e nomeia Marcelo Calero como Ministro da Cultura. Calero, ao assumir o Ministério, diz que sua principal missão e desafio é a de valorizar a pluralidade brasileira, ressaltando que em sua gestão, os mecanismos de financiamento serão aprimorados. O Ministro afirmou também que dará continuidade no que já vinha sendo feito.

Porém, atitudes do Ministro da Cultura apontam para o desmonte geral das políticas culturais e principalmente do MinC, visando apagar o legado dos governos anteriores. Pedro Vasconcellos, ex-diretor da Diretoria de Estudos e Monitoramento de Políticas Culturais da Secretaria de Políticas Culturais (SPC), declarou em seu perfil pessoal de uma rede social, que sem justificativa técnica ou jurídica, o cancelamento de parte da programação das Olimpíadas, levado a cabo por Calero, significa uma retaliação política à gestão de Juca Ferreira (ministro de Dilma). Vasconcellos fala também da exoneração de mais de 70 cargos comissionados que 
teve como justificativa a retirada de petistas da gestão, mas que acaba caminhando para uma desestruturação e interrupção de um longo processo.

Apesar de ser escancarada as intenções do governo Temer de destruir qualquer processo de construção mais sistematizado das politicas culturais no Brasil - ainda que insuficiente, porém com alguns avanços -, que ficou evidente em sua primeira medida de extinguir o Minc, isso não é exclusividade de sua gestão. Essa é a tônica da história das políticas culturais no Brasil. A descontinuidade e falta de políticas pensadas - e executadas a médio e longo prazo de fomento e manutenção da cultura é uma das grandes questões para superar as grandes dificuldades da produção cultural nas terras tupiniquins.

Quando prospectamos as intenções desse governo no que tange as políticas culturais para as mulheres a situação se agrava ainda mais, tendo em perspectiva, que com a consolidação do processo de impedimento, a nomeação de todos os ministros foi de homens, brancos e representantes das elites político-econômicas. Nenhuma mulher, negro/a, representações populares ou pessoas com trajetória nas causas populares ou de minorias políticas. Isso faz necessária uma especial vigilância sobre qual será (ou não será) a atenção desse governo às políticas culturais para as mulheres.

\section{Políticas culturais para mulheres no Brasil}

Marina Faria (2013, p.68) trata da relação do movimento feminista com a SPM (Secretaria de Promoção de Políticas para as Mulheres), criada em 2003, no governo Lula. A SPM e o movimento feminista desenvolveram os Planos Nacionais de Políticas para as Mulheres. O PNPM (Plano Nacional de Políticas para as Mulheres) de 2013 - 2015, como apresenta Eleonora Menicucci ${ }^{3}$ - a então Ministra de Estado Chefe da Secretaria de Políticas para as Mulheres - está inserido em um contexto político inédito no Brasil, o primeiro governo brasileiro presidido por uma mulher, Dilma Rousseff. O PNPM 2013 - 2015 aborda aspectos como: igualdade no mundo do trabalho e autonomia econômica; educação para igualdade e cidadania; saúde integral das mulheres, direitos sexuais e direitos reprodutivos; enfrentamento de todas as formas de violência contra a mulher; fortalecimento e participação das mulheres nos espaços de poder e decisão; desenvolvimento sustentável com igualdade econômica e social; direito à terra com igualdade para as mulheres do campo e da floresta;

\footnotetext{
${ }^{3}$ Eleonora Menicucci é a autora da apresentação do Plano Nacional de Políticas para as Mulheres, escrito no ano de 2013.
} 
cultura, esporte, comunicação e mídia; enfrentamento do racismo, sexismo e lesbofobia; e igualdade para as mulheres jovens, idosas e mulheres com deficiência.

No que diz respeito à cultura, entendendo-a enquanto um direito de todas/os, o PNPM 2013 - 2015 diz que esse direito deve ser garantido por políticas que ampliem o acesso aos meios de produção, difusão e da própria produção cultural. Tendo como objetivos gerais a construção de uma cultura igualitária e democrática, promover a visibilidade da contribuição das mulheres na cultura, garantindo o acesso feminino aos conteúdos e meios de produção cultural. Entre outras, promover, valorizar e estimular a participação e produção cultural das mulheres brasileiras. O MinC (Ministério da Cultura) é um dos órgãos responsáveis, junto com a SPM (Secretaria de Promoção de Políticas para as Mulheres) e outros, para colocar em pratica as ações, do segmento cultural, propostas pelo PNPM 2013 - 2015.

Para além do PNPM existem alguns editais específicos para as mulheres, por exemplo, na área do cinema, o Edital Carmen Santos de Cinema de Mulheres 2013, que apoiou 10 curtas-metragens de até 5 minutos e 6 médias-metragens de 26 minutos. O Edital Carmen Santos é uma parceria entre o MinC, através da Secretaria do Audiovisual, e a Secretaria de Políticas para as Mulheres. Segundo informações do site do MinC, o edital investiu cerca de $\mathrm{R} \$ 990.000,00$ e contou com um total de 417 propostas inscritas, demostrando que existe uma grande demanda para pouco incentivo. No ano de 2016, aconteceu a Mostra Carmen Santos, que exibiu, com entrada franca, 9 curtas- metragens e 6 médias-metragens premiados no edital Carmen Santos de 2013. Além da mostra cinematográfica, esse edital também desencadeou alguns debates sobre a situação das mulheres no cinema, em Brasília e no Rio de Janeiro.

Ainda em 2013, foi lançada a primeira edição do Edital Prêmio Funarte Mulheres nas Artes Visuais, que contemplou 10 projetos dos 630 habilitados e teve um investimento em torno de $\mathrm{R} \$ 700.000,00$ em premiação e $\mathrm{R} \$ 44.200$ para custos administrativos. O Edital Prêmio Funarte Mulheres nas Artes Visuais é uma parceira da FUNARTE com o Ministério da Cultura e a Secretária de Políticas para as Mulheres. "Esse edital visava selecionar iniciativas de proponentes do sexo feminino e propiciar o estímulo, reflexão e experiência artística de mulheres." (LIMA, 2015, p.9).

Diante dessas políticas culturais voltadas para mulheres, especificamente no cinema, onde "atualmente, a produção cinematográfica no Brasil depende inteiramente da dedução fiscal" (FARIA, 2013, p.74) nota-se que os estímulos ainda são poucos e que a equidade de gênero está longe de acontecer. Segundo, os únicos, dados da ANCINE (Agência Nacional do Cinema) - criada em 2001 - que abordam a relação de gênero da direção de filmes no Brasil, é de 2015 e mostra que dos 128 títulos lançados no ano, apenas 19 foram dirigidos por 
mulheres $(14,8 \%)$ e os homens comandaram 99 filmes $(77,3 \%) .10$ filmes $(7,8 \%)$ foram dirigidos por ambos.

No tocante à relação entre Mulheres e a produção literária, a história não é diferente. Dulcilei Lima (2015, p.4) apresenta uma pesquisa realizada por Regina Dalcastagnè em 2007 onde foram analisados todos os romances publicados num período de 15 anos pelas grandes editoras brasileiras. Do total de publicações, menos de $30 \%$ são de autoras mulheres e menos de $40 \%$ das personagens são mulheres. "De modo geral há uma aparente naturalização da invisibilidade de alguns grupos sociais nas produções culturais nacionais, reflexo da realidade brasileira em sua profunda desigualdade social, étnico-racial e de gênero." (LIMA, 2015, p. 5).

$\mathrm{Na}$ Arte, as mulheres foram excluídas desde o princípio, quando não podiam cursar aulas de "modelo vivo", Lima (2015, p.7) responsabiliza as instituições culturais e educacionais pela ausência das mulheres entre os grandes nomes da arte e da ciência. Pois sendo impedidas de estudar a técnica de modelo vivo não conseguiam desenvolver a pintura histórica, somente os gêneros - naturezas-mortas, retratos, paisagens - considerados menores pela Academia. Além do custo das mensalidades e anuidades que geralmente era cobrado o dobro para mulheres. "Em fins do século XIX no Brasil, as mulheres que desejavam profissionalizar-se enquanto artistas enfrentavam como obstáculos para o ingresso nos cursos superiores, as lacunas nos currículos" (LIMA, 2015, p. 7), devido a educação diferenciada que tinham no ensino secundário, onde aprendiam a ser "mulheres do lar" e os homens eram ensinados para o mundo do mercado de trabalho.

\footnotetext{
"Coube aos movimentos feministas solapar essa visão medieval de educação para as mulheres. A instrução era vista pelas feministas como ferramenta essencial na ampliação dos direitos políticos e sociais das mulheres, na profissionalização e, portanto aquisição de poder econômico (chave para se alcançar autonomia)" (LIMA, 2015, p. 8).
}

\section{Considerações Finais}

Atualmente nota-se que o Ministro da Cultura Marcelo Calero junto com Michel Temer continuam com o posicionamento de desmonte da cultura. Mesmo com a recriação do Ministério da Cultura por Temer, as ações que são tomadas nos mostra que a cultura no Brasil está sendo degolada. O cenário cultural vive um momento de fragilidade e instabilidade, onde decisões são tomadas e dias depois recuadas. Criticas são feitas pela atual gestão à gestão anterior ao invés de construírem estruturas de consolidação para a cultura. 
Juca Ferreira, ex-ministro da cultura, da uma declaração onde ele diz que "a credibilidade de uma gestão não se constrói com calúnias à gestão anterior, mas com seriedade, eficiência e transparência." (FERREIRA, Juca. 2016). Cancelar parte da programação das Olímpiadas que foi pensada e planejada na gestão de Juca Ferreira foi visto como uma atitude de manchar o legado da gestão anterior. Foram realizadas mais de 70 exonerações de cargos comissionados de todas as áreas da cultura, interrompendo trabalhos e projetos em andamento.

As políticas culturais no Brasil sofrem com problemas desde quando foram inauguradas, porém podemos perceber que na atual situação estão tomando cada vez mais o caminho de falecimento. Direitos sociais que foram bravamente conquistados estão sendo atacados e ameaçados. Os movimentos sociais de luta e resistência estão sendo criminalizados. O Temer está trazendo instabilidade para todas as áreas, inclusive para a cultura, junto com o Ministro Marcelo Calero que discursa sobre dar continuidade no que já vinha sendo feito e valorizando a pluralidade brasileira, só faz atacar gestões passadas a fim de dar credibilidade a sua gestão e ao próprio governo que o Brasil está vivendo.

Nesse sentido a grande questão das políticas públicas para as mulheres perpassa todas as questões das políticas culturais de maneira geral: pelas ausências, o autoritarismo e as descontinuidades. Porém, é preciso perceber que essa ausência, o autoritarismo e as descontinuidades é parte do repertório masculino de gestão pública. A ausência das políticas para as mulheres é também a ausência de mulheres nos espaços de tomadas de decisão. $\mathrm{O}$ autoritarismo é masculino, é militar (não só, mas também), é hierárquico e não é ativo em atenção as questões de gênero. E por fim, essas descontinuidades é fruto de disputas de poder de frações de homens com pouca ou quase nenhuma atenção à necessidade de se estabelecer políticas que caminhem na direção da equidade de gênero na dimensão das políticas culturais.

\section{Referências}

ANCINE. Informe preliminar de distribuição, exibição e lançamentos. 2015.

CALABRE, Lia. Política cultural no Brasil: um histórico. Salvador, I ENECULT Encontro de Estudos Multidisciplinares em cultura, 2005.

FARIA, Marina Sartório. A participação feminina na direção do cinema documentário brasileiro. Orientadora: Prof ${ }^{\mathrm{a}}$. Dr ${ }^{\mathrm{a}}$. Linda Rubim. Dissertação (mestrado) - Universidade Federal da Bahia, Instituto de Humanidades, Artes e Ciências Professor Milton Santos, Salvador, 2013. 
RELACult - Revista Latino-Americana de Estudos em Cultura e Sociedade e-ISSN 2016/Atual: 2525-7870 | e-ISSN 2015/2016: 2447-018X

LIMA, Dulcilei da Conceição. A mulher na produção cultural brasileira: invisibilidade e fomento. Salvador, XI ENECULT - Encontro de Estudos Multidisciplinares em cultura, 2015 .

MINISTÉRIO DA CULTURA. Edital Carmen Santos de cinema de mulheres. 2013.

MINISTÉRIO DA CULTURA. Edital Prêmio FUNARTE mulheres nas artes visuais. 2013.

Portal do MinC. Marcelo Calero é o novo ministro da cultura. 2016. Disponível em: http://www.cultura.gov.br/noticias-destaques/

lasset_publisher/OiKX3xlR9iTn/content/id/1341795 Acesso em 18 de agosto de 2016.

Portal G1. Câmara aprova prosseguimento do processo de impeachment no senado. Brasília, 2016. Disponível em: http://g1.globo.com/politica/processo-de-impeachment-dedilma/noticia/2016/04/camara-aprova-prosseguimento-do-processo-de-impeachment-nosenado.html Acesso em: 18 de agosto de 2016.

Portal G1. Processo de impeachment é aberto, e Dilma é afastada por até 180 dias. Brasília, 2016. Disponível em: http://g1.globo.com/politica/processo-de-impeachment-dedilma/noticia/2016/05/processo-de-impeachment-e-aberto-e-dilma-e-afastada-por-ate-180dias.html Acesso em: 18 de agosto de 2016

RUBIM, Antonio Albino Canelas. Políticas culturais no Brasil: tristes tradições, enormes desafio. In: RUBIM, Antonio Albino Canelas; BARBALHO, Alexandre (Orgs.). Políticas culturais no Brasil. Salvador: EDUFBA, 2007.

RUBIM, Linda. Cinemas contemporâneos da Argentina e do Brasil: diretoras em cena. Salvador, III ENECULT - Encontro de Estudos Multidisciplinares em Cultura, 2007.

SECRETARIA DE POLÍTICAS PARA AS MULHERES. Plano Nacional de Políticas para as Mulheres. 2013 - 2015. 